\title{
Comparison of the short-term safety and efficacy of transcarotid and transfemoral access routes for transcatheter aortic valve implantation
}

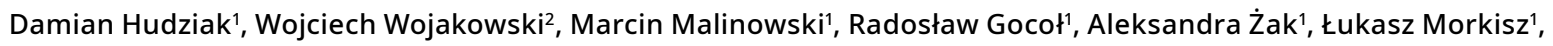 \\ Andrzej Ochała², Radosław Parma², Grzegorz Smolka², Joanna Ciosek², Adrianna Nowak², Michał Lelek², Marek A. Deja \\ 1 Department of Cardiac Surgery, Medical University of Silesia, Katowice, Poland \\ 2 Division of Cardiology and Structural Heart Diseases, Medical University of Silesia, Katowice, Poland \\ 3 1st Division of Cardiology, Medical University of Silesia, Katowice, Poland
}

\section{KEY WORDS}

aortic stenosis, transcarotid access, transcatheter aortic valve implantation

\section{EDITORIAL}

by Conrotto, Bruno, and D'Ascenzo, see p. 3
Correspondence to: Damian Hudziak, MD, PhD, Department of Cardiac Surgery, Medical University of Silesia, ul. Ziołowa 47, 40-635 Katowice, Poland, phone: +48323598644 , email: damhud@gmail.com Received: September 4, 2020. Revision accepted: December 1, 2020. Published online: December 3, 2020. Kardiol Pol. 2021; 79 (1): 31-38 doi:10.33963/KP.15697 Copyright by the Author(s), 2021

\section{ABSTRACT}

BACKGROUND Transfemoral access is the preferred approach for transcatheter aortic valve implantation (TAVI), as it is characterized by the lowest complication rate. In the majority of patients ineligible for transfemoral access, the transcarotid approach can be used.

AIMS This study aimed to compare short-term outcomes in 2 groups of patients treated with transcarotid or transfemoral TAVI.

METHODS A retrospective comparison included 265 patients in whom the TAVI procedure was performed between 2017 and 2019 (transcarotid TAVI, $n=33$; transfemoral TAVI, $n=232$ ). Preoperative characteristics, procedural and postprocedural outcomes, as well as 30-day mortality were assessed.

RESULTS Compared with the transfemoral TAVI group, patients undergoing transcarotid TAVI presented with a higher New York Heart Association (NYHA) functional class (median [interquartile range (IQR)], 3 [3-3] vs 2 [2-3]; $P<0.001$ ), a higher surgical risk (median [IQR] EuroSCORE II, 6 [4.8-10.7] vs 4.8 [2.8-7.9]; $P=0.003$ ), and a higher incidence of peripheral artery disease ( $36.4 \%$ vs $18.1 \% ; P=0.035$ ). The median (IQR) procedure duration in the transcarotid TAVI group was shorter than in patients undergoing transfemoral TAVI (65 [60-80] min vs 90 [80-110] min; $P<0.001$, respectively). In both study groups, we noted a high percentage of procedural success (transcarotid vs transfemoral TAVI, $96.9 \%$ vs $97.2 \% ; P=0.66$ ). We found no significant differences between transcarotid TAVI and transfemoral TAVI in terms of periprocedural and 30-day mortality as well as the number of strokes. Regardless of the access route chosen, echocardiographic parameters and the NYHA class similarly improved compared with preprocedural data.

CONCLUSIONS Despite posing a higher baseline risk and presenting a greater anatomic complexity, transcarotid access is safe and associated with 30-day outcomes similar to those observed for transfemoral access. Importantly, procedural time was short and no periprocedural strokes or vascular complications were reported.

INTRODUCTION According to the guidelines of international societies (European Society of Cardiology, European Association for Cardio-Thoracic Surgery, American College of Cardiology, and American Heart Association), transcatheter aortic valve implantation (TAVI) using access through the femoral artery is a preferred treatment method in patients at high- and medium-risk patients with severe aortic stenosis. Also, according to the Society of Thoracic Surgery and based on EuroSCORE, it can be recommended in patients at lower surgical risk who meet the criteria favoring TAVI over surgical aortic valve replacement. ${ }^{1,2}$ Unfortunately, the transfemoral access route can be used in only about $80 \%$ to $85 \%$ of patients referred for 


\section{WHAT'S NEW?}

To our best knowledge, this is the first study reporting the early outcomes of the largest group of patients after transcarotid transcatheter aortic valve implantation (TAVI) in Poland. The transcarotid approach is less invasive than transapical and transaortic access routes. Our results show the similar outcomes and high safety of transcarotid access compared with the preferred transfemoral access. Therefore, the transcarotid approach may be considered a first-choice alternative in TAVI when transfemoral access cannot be used.

TAVI, as a small vessel diameter and the presence of peripheral artery disease (PAD) constitute contraindications to this approach..$^{3-6}$ In the remaining patients, one of the alternative access routes has to be used: transapical, transaortic, transcarotid, trans-subclavian, or transcaval. Transapical access is associated with chest injury caused by minithoracotomy and it poses a higher risk of mortality and bleeding complications than the transfemoral approach. ${ }^{7-9}$ On the other hand, access through the subclavian artery is limited in patients who underwent coronary artery bypass grafting in the past, especially with the left internal mammary artery to the left anterior descending artery. Also, the risk is higher after pacemaker implantation in the subclavian area. ${ }^{10}$

In 2010, Modine et $\mathrm{al}^{11}$ reported on the first TAVI procedure performed through the left common carotid artery (CCA), which aroused great interest. Since then, this approach has been used as an alternative treatment method in patients ineligible for transfemoral TAVI. ${ }^{12-14}$ The aim of our study (a registry including all consecutive patients treated in a large academic medical center) was to evaluate the early safety outcomes and efficacy of transcarotid TAVI compared with transfemoral TAVI.

METHODS In this retrospective study, we enrolled consecutive patients with severe symptomatic aortic stenosis who were treated in our hospital with transfemoral or transcarotid TAVI between 2017 and 2019. All patients provided written informed consent to undergo the TAVI procedure according to eligibility evaluation. No institutional review board or ethics committee approval was required for this study. The results were presented in line with the Valve Academic Research Consortium-2 (VARC-2) consensus. ${ }^{15}$ The Heart Team decided about the access route used for valve implantation. The decision was based on the findings from multislice computed tomography (MSCT) of the aorta and peripheral arteries, transthoracic echocardiography, and coronary angiography. The 3 Mensio program (Pie Medical Imaging, Bilthoven, The Netherlands) was used for the analysis of scans. Patients with $\mathrm{PAD}$, extensive calcifications, critical iliac artery stenosis, or extreme tortuosity, as well as a small iliac artery diameter ( $<6 \mathrm{~mm})$ were deemed ineligible for transfemoral TAVI. Also, significant aortic disease at the level of the thoracic and abdominal aorta, such as aneurysm, presence of an aortic stent graft, large thrombus, chronic aortic dissection, or excessive aortic tortuosity, favored the choice of transcarotid access. In this group of patients, the alternative method of access was discussed (transcarotid or transapical). A detailed protocol for the assessment of transcarotid access and the surgical technique was presented elsewhere. ${ }^{16}$ The method of achieving transfemoral access for TAVI did not differ from that described by Grube et al. ${ }^{17}$ Based on the analysis of MSCT scans, patients had to have the carotid artery diameter of at least $5.5 \mathrm{~mm}$, no significant ipsi- or contralateral $(>50 \%)$ CCA stenosis, and no significant calcifications in order to be eligible for transcarotid TAVI. All procedures were performed by the Heart Team, in a hybrid room, and under full or local anesthesia. All patients were given antibiotics (cephazolin $1.5 \mathrm{~g}$ ) as prophylaxis against infectious endocarditis. After placing a vascular access catheter (6F) in the carotid or femoral artery, heparin was administered (100 U/kg; activated clotting time $>250 \mathrm{~s}$ ). Patients were monitored during the whole procedure: intra-arterial blood pressure and central venous pressure measurement, evaluation of arterial blood saturation, and electrocardiography were performed. In addition, cerebral oximetry (INVOS 5100C, Medtronic, Dublin, Ireland) was monitored during transcarotid TAVI. In the majority of procedures, transthoracic echocardiography was performed. In selected cases, transoesophageal echocardiography was also used. The electrode for pacing was placed using a $6 \mathrm{~F}$ sheath through the internal jugular vein or the femoral vein. Follow-up arteriography was carried out after removing the whole system from the carotid artery.

Statistical analysis Data were presented as mean (SD) if they followed normal distribution or as median (interquartile range [IQR]) when normality assumptions (Shapiro-Wilk test) were not met. The study groups were compared using the Mann-Whitney rank sum test. Categorical data were expressed as a percentage and compared with the $\mathrm{X}^{2}$ or Fisher exact tests. Two-way repeated-measures analysis of variance was carried out to test for the difference before and after the procedure between the groups. For 2-way repeated-measures analysis of variance, non-normally distributed data were normalized by logarithmic transformation. All statistical analyses were performed with the SigmaPlot program, version 12.5 (Systat Software, San Jose, California, Unites States) and the IBM SPSS software, version 26.0 (IBM Corp., Armonk, New York, Unites States). A $P$ value less than 0.05 was considered significant. 
TABLE 1 Characteristics of the study patients

Characteristics

Transcarotid TAVI $(n=33) \quad$ Transfemoral TAVI $(n=232) \quad P$ value

\begin{tabular}{|c|c|c|c|}
\hline Age, y & $77(72-85)$ & $79(74-83)$ & 0.61 \\
\hline Male sex & $17(51.5)$ & $101(43.5)$ & 0.45 \\
\hline $\mathrm{BMI}, \mathrm{kg} / \mathrm{m}^{2}$ & $28(24-31.5)$ & $28(25-32)$ & 0.54 \\
\hline NYHA class & $3(3-3)$ & $2(2-3)$ & $<0.001$ \\
\hline EuroSCORE II, \% & $6(4.8-10.7)$ & $4.8(2.8-7.9)$ & 0.003 \\
\hline \multicolumn{4}{|l|}{ Cardiac comorbidities } \\
\hline Prior MI & $11(33.3)$ & $51(22)$ & 0.18 \\
\hline Prior cardiac surgery & $10(30.3)$ & $67(28.9)$ & 0.84 \\
\hline Prior PCI & $14(42.4)$ & $88(37.9)$ & 0.7 \\
\hline Atrial fibrillation & $9(27.3)$ & $62(26.7)$ & $>0.99$ \\
\hline Pacemaker & $1(3)$ & $34(14.7)$ & 0.09 \\
\hline Hypertension & $33(100)$ & $209(90.1)$ & 0.09 \\
\hline \multicolumn{4}{|l|}{ Other comorbidities } \\
\hline Dyslipidemia & $24(72.7)$ & $175(75.4)$ & 0.83 \\
\hline Diabetes & $19(57.6)$ & $100(43.1)$ & 0.13 \\
\hline COPD & $8(24.2)$ & $29(12.5)$ & 0.09 \\
\hline PAD & $12(36.4)$ & $42(18.1)$ & 0.03 \\
\hline Prior stroke & $1(3)$ & $20(8.6)$ & 0.48 \\
\hline Prior TIA & 0 & $6(2.6)$ & $>0.99$ \\
\hline \multicolumn{4}{|l|}{ Laboratory parameters } \\
\hline TNT, ng/ml & $0.021(0.01-0.03)$ & $0.019(0.01-0.003)$ & 0.68 \\
\hline Creatinine, mg/dl & $1.08(0.87-1.28)$ & $1.05(0.89-1.05)$ & 0.88 \\
\hline Hemoglobin, g/l & $12.9(11.4-14.3)$ & $12.7(11.8-13.9)$ & 0.67 \\
\hline \multicolumn{4}{|c|}{ Echocardiographic parameters } \\
\hline LVEF, \% & $50(45-55)$ & $55(45-60)$ & 0.56 \\
\hline$P G_{\max }, \mathrm{mm} \mathrm{Hg}$ & $69(59-89)$ & $73(60-90)$ & 0.52 \\
\hline $\mathrm{PG}_{\text {mean }}, \mathrm{mm} \mathrm{Hg}$ & $42(35.5-54.5)$ & $42(34-55.5)$ & 0.64 \\
\hline AVA, $\mathrm{cm}^{2}$ & $0.7(0.6-0.8)$ & $0.7(0.6-0.8)$ & 0.46 \\
\hline $\mathrm{V}_{\max }, \mathrm{m} / \mathrm{s}$ & $4.1(3.8-4.6)$ & $4.2(3.7-4.6)$ & 0.71 \\
\hline
\end{tabular}

Data are presented as number (percentage) or median (interquartile range).

Abbreviations: AVA, aortic valve area; BMI, body mass index; COPD, chronic obstructive pulmonary disease; LVEF, left ventricular ejection fraction; MI, myocardial infarction; NYHA, New York Heart Association; PAD, peripheral artery disease; PCI, percutaneous coronary intervention; $P G_{\max }$, maximal aortic valve pressure gradient; $P G_{\text {mean }}$, mean aortic valve pressure gradient; TAVI, transcatheter aortic valve implantation; TIA, transient ischemic attack; TNT, troponin $\mathrm{T}$; $\mathrm{V}_{\max }$, peak instantaneous transaortic velocity

RESULTS This retrospective study enrolled 265 patients (transcarotid TAVI, $\mathrm{n}=33$; transfemoral TAVI, $\mathrm{n}=232$ ) treated in the Upper Silesian Medical Center of Medical University of Silesia in Katowice, Poland, between 2017 and 2019. The characteristics of the study patients are presented in TABLE 1. There were no differences between the transfemoral TAVI and transcarotid TAVI groups in terms of median (IQR) age (77 [72-85] years vs 79 [74-83] years; $P=0.61)$ or male sex $(43.5 \%$ vs $51.5 \% ; P=0.45)$.
The baseline median (IQR) New York Heart Association (NYHA) functional class was higher in the transcarotid TAVI group (3 [3-3] vs 2 [2-3]; $P<0.001)$. Patients undergoing transcarotid TAVI had a higher incidence of PAD than those undergoing transfemoral TAVI (36.6\% vs $18.1 \% ; P=0.03$ ). Both study groups did not show significant differences in terms of other comorbidities. Preoperative blood test results (tropo$\operatorname{nin} \mathrm{T}$, creatinine, and hemoglobin levels) and echocardiographic parameters (left ventricular 
TABLE 2 Perioperative outcomes of the study patients

Variable

Transcarotid TAVI $(n=33) \quad$ Transfemoral TAVI $(n=232) \quad P$ value

\begin{tabular}{llll} 
Procedural success & $32(96.9)$ & $226(97.2)$ & 0.66 \\
\hline Procedural time, min & $65(60-80)$ & $90(80-110)$ & $<0.001$ \\
\hline Prosthesis dislocation & 0 & $5(2.2)$ & 0.74 \\
\hline General anaesthesia & $33(100)$ & $110(47.4)$ & $<0.001$ \\
\hline Valve-in-valve procedure & 0 & $17(7.3)$ & 0.14 \\
\hline Balloon aortic predilatation & $4(12.1)$ & $51(22)$ & 0.25 \\
\hline Balloon aortic postdilatation & $7(21.2)$ & $40(17.2)$ & 0.62 \\
\hline Coronary artery occlusion & 0 & $3(1.3)$ & $>0.99$ \\
\hline IABP & 0 & $2(0.9)$ & $>0.99$ \\
\hline Inotropic drugs & $6(18.2)$ & $64(27.6)$ & 0.29 \\
\hline Temporary pacemaker & $9(27.3)$ & $54(23.3)$ & $>0.99$ \\
\hline Procedural mortality & $1(3)$ & $6(2.6)$ & 0.66 \\
\hline Types of prostheses & & & 0.25 \\
\hline Medtronic Evolut R & $24(72.7)$ & $123(53)$ & 0.05 \\
\hline Edwards-Sapien valve & $8(24.2)$ & $56(24.1)$ & 0.83 \\
\hline Abbott valve & $1(3.1)$ & $36(15.6)$ & 0.12 \\
\hline Symetis valve & 0 & $16(6.8)$ & 0.24 \\
\hline Boston valve & 0 & $1(0.4)$ & 0.25 \\
\hline
\end{tabular}

Data are presented as number (percentage) or median (interquartile range).

Abbreviations: IABP, intra-aortic balloon pump; others, see TABLE 1

ejection fraction, maximal aortic valve pressure gradient $\left[\mathrm{PG}_{\max }\right]$, mean aortic valve pressure gradient $\left[\mathrm{PG}_{\text {mean }}\right]$, aortic valve area, and peak instantaneous transaortic velocity $\left[\mathrm{V}_{\max }\right]$ ) were similar between the groups. The median surgical risk assessed by EuroSCORE II was higher in the transcarotid TAVI group compared with the transfemoral TAVI group (6 [4.8-10.7] vs 4.8 [2.8-7.9]; $P=0.003$ ].

The periprocedural results of the study patients are shown in TABLE2. The procedural success rate was high in both groups: $96.9 \%$ for transcarotid TAVI and $97.2 \%$ for transfemoral TAVI $(P=0.66)$. All patients undergoing transcarotid TAVI and only $47.4 \%$ of those undergoing transfemoral TAVI were operated on under general anesthesia $(P<0.001)$. The types of TAVI prostheses used and their percentage distribution were similar between the groups (FIGURE1). However, there was a tendency to use self-expanding valves (CoreValve, Evolut R, Medtronic, Minneapolis, Minnesota, United States) during transcarotid TAVI procedures $(72.2 \%$ vs $53 \% ; P=0.05)$. The median (IQR) procedure duration was substantially lower in the transcarotid TAVI group than in the transfemoral TAVI group (65 [60-80] min vs 90 [80-110] min; $P<0.001)$. We noted no differences regarding procedural parameters such as balloon valvuloplasty performed before $(12.1 \%$ vs $22 \% ; P=0.25)$ or after TAVI $(21.2 \%$ vs $17.2 \%$; $P=0.62$ ) and the planned use of temporary rapid pacing during implantation $(24.2 \%$ vs $23.3 \%$; $P>0.99)$. There was a low rate of neurological complications in the transcarotid TAVI group (no strokes and a single case of transient ischemic attack [TIA; 3\%]) (TABLE3). In the transfemoral TAVI group, the rate of strokes was $2.2 \%$ ( $\mathrm{n}=5 ; \mathrm{P}=0.86$ [versus the transcarotid TAVI group]) and of TIA, $1.7 \%(\mathrm{n}=3 ; P=0.86$ [versus transcarotid TAVI group]). A low number of VARC-2 events was noted in both transcarotid and transfemoral TAVI groups (mortality during the procedure [3\% vs $2.6 \% ; P=0.66$ ], 30-day mortality [ $6.06 \%$ vs $4.32 \% ; P=0.99]$, myocardial infarction [3\% vs $3.4 \% ; P=0.69$ ], vascular complications [0\% vs $1.7 \% ; P>0.99]$, life-threatening bleeding [0\% vs $1.7 \% ; P>0.99$ ], coronary artery occlusion [0\% vs $1.3 \%$; $P>0.99$ ], dysfunction of the prosthesis that required conversion to surgical aortic valve replacement [ $0 \%$ vs $0 \% ; P>0.99$ ], and acute renal failure that required renal replacement therapy [0\% vs $0 \% ; P>0.99]$ ). The median time that patients spent in the intensive care unit and the median total hospitalization time were also similar in both study groups (2 [2-3] vs 3 [2-4] days; $P=0.21$ and 6 [6-7] vs 6.5 [5-8] days; $P=0.19$ in the transcarotid and transfemoral TAVI groups, respectively). In 
A

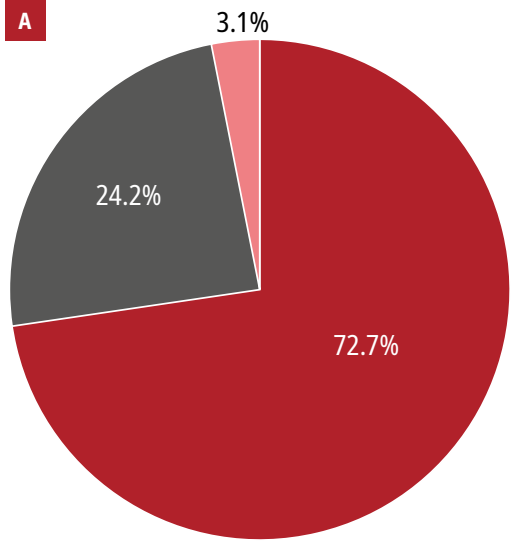

Transcarotid TAVI
B

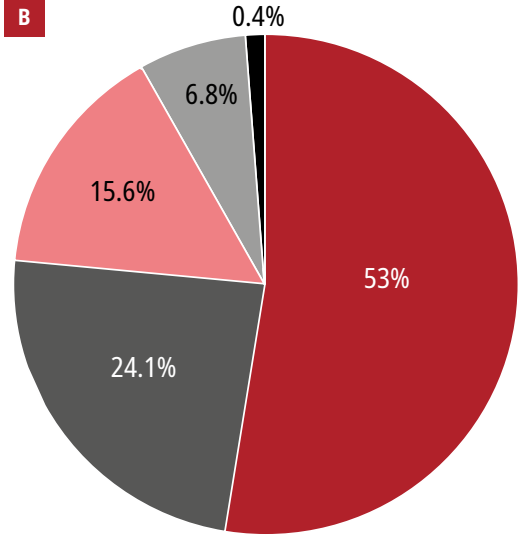

Transfemoral TAVI
- CoreValve Evolut R

(Medtronic, Minneapolis,

Minnesota, United States)

- Edwards-Sapien 3 ultra (Edwards Lifesciences Corp., Irvine, California, United States)

- Portico

(Abbott Vascular, Santa Clara,

California, United States)

- Acurate neo

(Symetis, Ecublens, Switzerland)

- Lotus

(Boston Scientific, Natick, Massachusetts, United States)

FIGURE 1 Types of valve prostheses used during transcarotid (A) and transfemoral (B) transcatheter aortic valve implantation procedures

Abbreviations: See TABLE 1

\section{TABLE 3 Postoperative outcomes of the study patients}

\begin{tabular}{|c|c|c|c|}
\hline Variable & Transcarotid TAVI $(n=33)$ & Transfemoral TAVI $(\mathrm{n}=\mathbf{2 3 2})$ & $P$ value \\
\hline MI & $1(3)$ & $8(3.4)$ & 0.69 \\
\hline Life-threatening bleeding & 0 & $4(1.7)$ & $>0.99$ \\
\hline TIA & $1(3)$ & $4(1.7)$ & 0.86 \\
\hline Stroke & 0 & $5(2.2)$ & 0.86 \\
\hline Tamponade & $1(3)$ & $3(1.3)$ & 0.4 \\
\hline Major vascular complication & 0 & $4(1.7)$ & $>0.99$ \\
\hline Mechanical ventilation time, min & $240(90-390)$ & $442.5(285-558.7)$ & $<0.001$ \\
\hline ICU stay, $d$ & $2(2-3)$ & $3(2-4)$ & 0.21 \\
\hline Hospital stay, d & $6(6-7)$ & $6.5(5-8)$ & 0.19 \\
\hline Blood transfusion & $3(9.1)$ & $26(11.2)$ & 0.49 \\
\hline New atrial fibrillation & $2(6.3)$ & $17(7.3)$ & 0.88 \\
\hline New pacemaker implantation & $5(15.1)$ & $28(12.1)$ & 0.77 \\
\hline TNT, ng/ml & $0.138(0.11-0.22)$ & $0.131(0.08-0.19)$ & 0.12 \\
\hline Creatinine, $\mathrm{mg} / \mathrm{dl}$ & $1.05(0.86-1.35)$ & $1.05(0.86-1.31)$ & 0.71 \\
\hline Hemoglobin, g/dl & $11.3(9.9-11.9)$ & $10.7(9.8-11.9)$ & 0.28 \\
\hline NYHA class & $2(1-2)$ & $1(1-1)$ & 0.03 \\
\hline 30-day mortality & $2(6.06)$ & $10(4.32)$ & 0.99 \\
\hline Wound infection & 0 & $7(3)$ & 0.6 \\
\hline \multicolumn{4}{|l|}{ Echocardiographic parameters } \\
\hline LVEF, \% & $55(50-60)$ & $55(45-56)$ & 0.17 \\
\hline$P G_{\text {max }}, \mathrm{mm} \mathrm{Hg}$ & $15(12.6-18.7)$ & $17(13-22.7)$ & 0.64 \\
\hline $\mathrm{PG}_{\text {mean }}, \mathrm{mm} \mathrm{Hg}$ & $8(6-10)$ & $9(7-12)$ & 0.54 \\
\hline $\mathrm{V}_{\text {max }^{\prime}} \mathrm{m} / \mathrm{s}$ & $1.9(1.7-2.1)$ & $2.0(1.8-2.4)$ & 0.07 \\
\hline PVL grade $>2$ & $2(6.1)$ & $28(12.1)$ & 0.46 \\
\hline
\end{tabular}

Data are presented as number (percentage) or median (interquartile range).

Abbreviations: ICU, intensive care unit; PVL, paravalvular leak; others, see TABLE1 

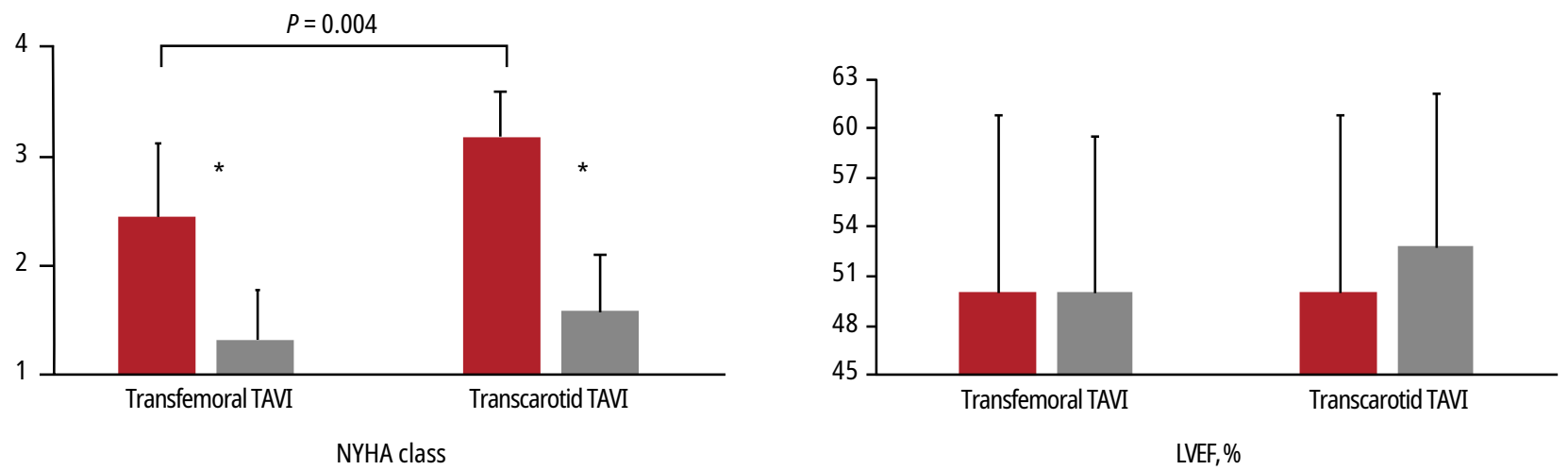

c
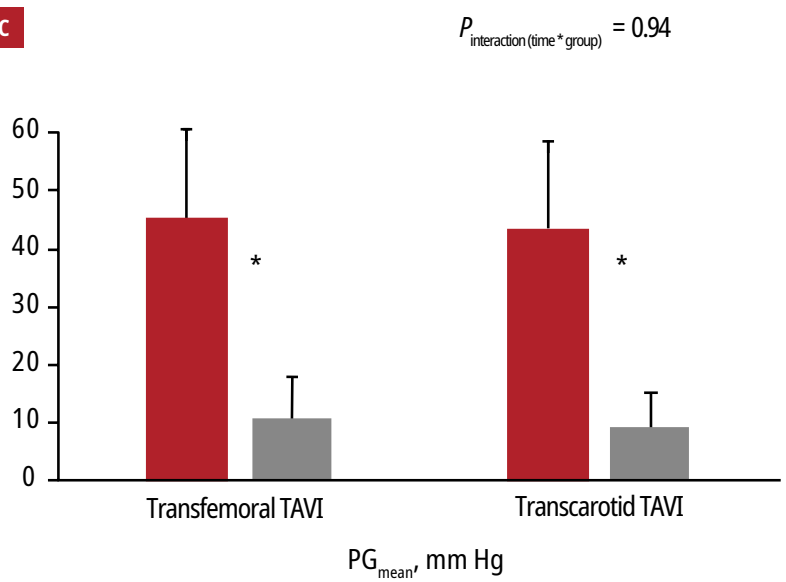

D $P_{\text {interation(time*group) }}=0.8$

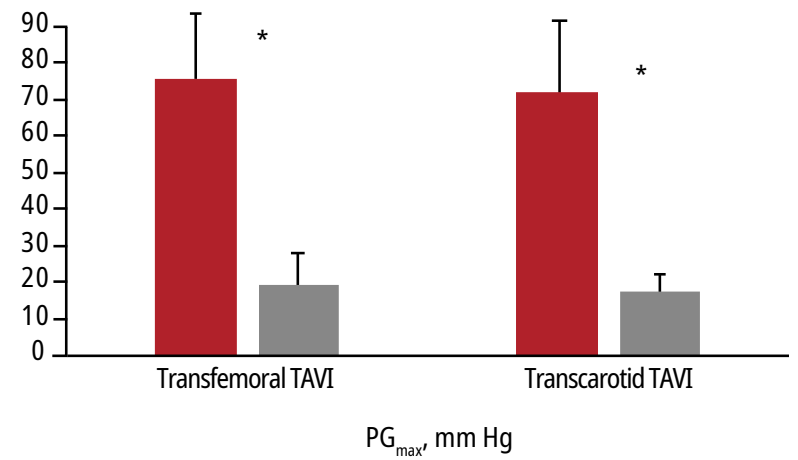

Before the procedure

After the procedure

FIGURE 2 Postoperative outcomes of transcarotid and transfemoral transcatheter aortic valve implantation compared between the study groups and with the preoperative values: A - New York Heart Association functional class; B - left ventricular ejection fraction; C - mean aortic valve pressure gradient; D - maximal aortic valve pressure gradient. Data normalized by logarithmic transformation are presented as mean (SD). Asterisks denote $P<0.001$.

the transfemoral TAVI group, the median (IQR) time of intubation was 442.5 (285-558.7) $\mathrm{min}$ utes compared with $240(90-390)$ minutes in the transcarotid TAVI group $(P<0.001)$. The rates of new-onset atrial fibrillation $(6.3 \%$ vs $7.3 \%$; $P=0.88)$ and need for permanent pacemaker implantation ( $15.1 \%$ vs $12.2 \%$; $P=0.77$ ) were similar in both groups. In a similar percentage of patients requiring temporary pacing after the procedure (9 of 33 patients [27.3\%] vs 54 of 232 patients [23.3\%] in the transcarotid and transfemoral TAVI groups, respectively; $P>0.99$ ), conduction abnormalities subsequently resolved and in-hospital permanent pacemaker implantation was avoided (4 of 9 patients $48.2 \%$ vs 26 of 54 patients [44.4\%] in the transcarotid and transfemoral TAVI groups, respectively; $P>0.99$ ). Patients from the transcarotid TAVI group did not require more blood transfusions during the early postoperative pe$\operatorname{riod}(9.1 \%$ vs $11.2 \% ; P=0.49)$ and we observed no wound infections following the procedure. The comparison of changes in echocardiographic parameters (left ventricular ejection fraction, $P G_{\text {max }}$, and $P G_{\text {mean }}$ ) and the NYHA functional class showed no significant differences between the study groups (FIGURE 2). Regardless of the access route used, after the procedure, we have noted a similar reduction in the aortic valve pressure gradient $\left(P G_{\max }\right.$ and $P G_{\text {mean }}$ ) and an improved NYHA class (FIGURE 2) No case of periprocedural myocardial infarction meeting the VARC-2 criteria was reported.

DISCUSSION Transfemoral access for TAVI is the most commonly used method in Europe and North America because of its minimal invasiveness and high safety. ${ }^{18}$ The introduction of effective access site closure devices (Proglide, Manta) and the reduction of the access sheath size expand TAVI accessibility to patients with 
peripheral vessels of small diameter. However, despite these advancements, there are still patients who need alternative access routes for TAVI. In our study group, transfemoral TAVI was performed in 232 out of all 274 TAVI procedures, which accounted for a rate of about $85 \%$. This is in line with findings reported by other authors. ${ }^{19,20}$ In numerous centers, transapical access represents the second most commonly chosen approach; however, it is associated with higher mortality and more frequent bleeding complications ${ }^{7,8,21}$ compared with transfemoral TAVI. The CCA, owing to its anatomy and superficial location, provides convenient access for a cardiac surgeon. The technique of carotid artery preparation is similar to surgical endarterectomy and requires meticulous manipulation with paying special attention to the laryngeal nerve and the jugular vein. The most common local complications related to obtaining access include damage to the laryngeal nerve, local hematoma, and wound infection..$^{22}$ In our study group, we did not observe any of these complications. The biggest concern about transcarotid access for TAVI lies in the risk of neurologic complications (stroke, TIA). These were seen in $3 \%$ of our study patients in the transcarotid TAVI group (a single case of TIA that resolved after 2 hours) and $3.9 \%$ of the patients in the transfemoral TAVI group. In a meta-analysis by Wee et $a l,{ }^{23}$ the rate of cerebrovascular events in a group of 364 patients undergoing transcarotid TAVI was $3.8 \%$. Chamandi et $\mathrm{al}^{24}$ compared transcarotid TAVI with transapical and transaortic approaches and showed similar rates of stroke risk $(2.1 \%$ in the transcarotid-access group and $3.5 \%$ in the transapical/transaortic-access group). On the other hand, Zhao et $\mathrm{al}^{25}$ and Liu et $\mathrm{al}^{26}$ analyzed transfemoral and transapical access routes for TAVI and reported the following rates of neurologic complications: $4 \%$ vs $2.2 \%$ for transfemoral TAVI, respectively, and $4.7 \%$ vs $2.6 \%$ for transapical TAVI, respectively; thus, no difference between both approaches was demonstrated. According to Mylotte et al, ${ }^{13}$ the occurrence of neurologic complications (3.1\% in 96 patients) during the transcarotid TAVI procedure may be caused by: 1) embolization of carotid artery plaque due to arterial puncture and instrumentation; 2) access site trauma providing a nidus for thrombosis with subsequent embolization; 3) inadequate collateral perfusion through the circle of Willis; and 4) embolization of debris during balloon valvuloplasty or transcatheter heart valve implantation. The key approach to minimize the number of cerebral events seems to include a proper patient eligibility evaluation based on MSCT findings, choice of the artery of a larger diameter, lower tortuosity, being less calcified, and having a more favorable spatial relationship between the virtual
CCA centerline and the plane of the aortic annulus. Additionally, Mylotte et $\mathrm{al}^{13}$ and Debry et $\mathrm{al}^{27}$ suggested expanding diagnostic workup with the use of Doppler ultrasonography and magnetic resonance imaging. The results of brain magnetic resonance imaging in a small group of patients after transfemoral TAVI and transcarotid TAVI described by Stańska et al ${ }^{28}$ showed that carotid access was safe and did not increase the risk of neurologic complications. It is estimated that $70 \%$ to $80 \%$ of transcarotid TAVI procedures are performed through the left CCA, ${ }^{23,27}$ although some operators still prefer the right CCA. In our analysis, $97 \%$ of patients have the procedure performed through the left CCA. The minimal diameter of CCA has not been agreed on, but, in our opinion, it should be at least $6 \mathrm{~mm} .^{23}$ The smallest diameter of the left carotid artery used by our team for TAVI was $5.4 \mathrm{~mm}$. We performed all transcarotid TAVI procedures in patients under general anesthesia. In our view, general anesthesia combined with intubation increases safety by reducing uncontrolled movements of the patient. According to Debry et al, ${ }^{27}$ a lower rate of stroke $(0 \%$ vs $8.1 \% ; P<0.001)$ and shorter hospitalization time (approximately 2 days) represent the advantages of local anesthesia over general anesthesia. The results of most reports on transcarotid and transfemoral TAVI showed a satisfactory safety profile of both approaches. Also, transcarotid TAVI compared favorably with transfemoral TAVI in terms of procedural success, perioperative and 30-day mortality, as well as other VARC-2 endpoints. ${ }^{13,23,24,27,29-31}$ This trend was also confirmed by our findings (TABLES 2 and 3). Paravalvular regurgitation, like leaflet thrombosis, structural valve deterioration, prosthesis-patient mismatch, and endocarditis, can lead to a faster development of valve dysfunction. ${ }^{32}$ Our analysis showed no correlation between the severity of paravalvular regurgitation and the type of access route used. Compared with alternative accesses through the chest (transapical and transaortic), we did not observe any influence of the approach used on mortality, occurrence of neurologic complications, rate of permanent pacemaker implantation, and vascular complications. However, recent registries reported a lower incidence of atrial fibrillation (3.2\% vs $19 \%)$, bleeding ( $4.3 \%$ vs $19.9 \%$ ), acute renal failure (0\% vs $12.1 \%$ ), and shorter time of hospitalization (6 vs 8 days) in transcarotid TAVI compared with alternative access routes. ${ }^{28}$ Data from the French TAVI Registry of 21611 patients, including 914 indivuduals undergoing transcarotid TAVI, showed the safety of transcarotid access. ${ }^{33}$ The safety of access through the carotid artery with no excess of 30-day mortality was also confirmed in an analysis of 11033 patients treated between 2013 and 2015 in France. ${ }^{34}$ At the early stage 
of the adoption of CCA access, a significantly higher frequency of stroke, myocardial infarction, wound infections, and renal failure was observed compared with patients undergoing transfemoral TAVI. Still, patients selected for transcarotid TAVI have more comorbidities and present a higher baseline risk than those undergoing transfemoral TAVI. ${ }^{34}$

Study limitations The presented analysis had several limitations. The study was retrospective, nonrandomized, and single-center. Only the early results were assessed. Patients in the transcarotid TAVI group were more symptomatic and had a higher EuroSCORE II risk than those in the transfemoral TAVI group. On the other hand, all transcarotid TAVI procedures were performed in a consistent way, according to the institutional standard operating procedures. Importantly, in all patients, transcarotid TAVI was performed under brain oxygenation monitoring.

Conclusions Based on our registry, we can assume that transcarotid access for TAVI is safe and leads to outcomes similar to those of the preferred transfemoral access. It can be recommended as the first-choice secondary access route in patients who are ineligible for transfemoral TAVI.

\section{ARTICLE INFORMATION}

\section{CONFLICT OF INTEREST None declared.}

OPEN ACCESS This is an Open Access article distributed under the terms of the Creative Commons Attribution-NonCommercial-NoDerivatives 4.0 International License (CC BY-NC-ND 4.0), allowing third parties to download articles and share them with others, provided the original work is properly cited, not changed in any way, distributed under the same license, and used for noncommercial purposes only. For commercial use, please contact the journal office at kardiologiapolska@ptkardio.pl.

HOW TO CITE Hudziak D, Wojakowski W, Malinowski M, et al. Comparison of the short-term safety and efficacy of transcarotid and transfemoral access routes for transcatheter aortic valve implantation. Kardiol Pol. 2021; 79: 31-38. doi:10.33963/KP.15697

\section{REFERENCES}

1 Baumgartner H, Falk V, Bax JJ, et al; ESC Scientific Document Group. 2017 ESC/ EACTS guidelines for the management of valvular heart disease. Eur Heart J. 2017; 38: 2739-2791.

2 Nishimura RA, Otto CM, Bonow RO, et al. 2017 AHA/ACC focused update of the $2014 \mathrm{AHA} / \mathrm{ACC}$ guideline for the management of patients with valvular heart disease: a report of the American College of Cardiology/American Heart Association Task Force on clinical practice guidelines. J Am Coll Cardiol. 2017; 70: 252-289.

3 Auffret V, Lefevre T, Van Belle E, et al. Temporal trends in transcatheter aortic valve replacement in France: FRANCE 2 to FRANCE TAVI. J Am Coll Cardiol. 2017; 70: 42-55.

4 Grover FL, Vemulapalli S, Carroll J, et al. STS/ACC TVT Registry. 2016 annual report of the Society of Thoracic Surgeons/American College of Cardiology Transcatheter Valve Therapy Registry. J Am Coll Cardiol. 2017; 69: 1215-1230.

5 Reardon MJ, Adams DH, Coselli JS, et al. Selfexpanding transcatheter aortic valve replacement using alternative access sites in symptomatic patients with severe aortic stenosis deemed extreme risk of surgery. J Thorac Cardiovasc Surg. 2014; 148: 2869-2876.

6 Hayashida K, Lefevre T, Chevalier B, et al. Transfemoral aortic valve implantation new criteria to predict vascular complications. J Am Coll Cardiol Intv. 2011; 4: 851-858.

7 Li $X$, Kong $M$, Jiang $D$, et al. Comparison 30-day clinical complications between transfemoral versus transapical aortic valve replacement for aortic stenosis: a meta-analysis review. J Cardiothorac Surg. 2013; 8: 168.

8 Chandrasekhar J, Hibbert B, Ruel M, et al. Transfemoral vs. non-transfemoral access for transcatheter aortic valve implantation: a systematic review and meta-analysis. Can J Cardiol. 2015; 31: 1427-1438.
9 Toggweiler S, Leipsic J, Binder RK, et al. Management of vascular access in transcatheter aortic valve replacement part 1: basic anatomy, imaging, sheaths, wires, and access routes. JACC Cardiovasc Interv. 2013; 6: 643-653.

10 Kallinikou Z, Berger A, Ruchat $P$, et al. Transcutaneous aortic valve implantation using the carotid artery access: feasibility and clinical outcomes. Arch Cardiovasc Dis. 2017; 110: 389-394.

11 Modine T, Lemesle G, Azzaoui R, et al. Aortic valve implantation with the CoreValve ReValving System via left carotid artery access: first case report. J Thorac Cardiovasc Surg. 2010; 140: 928-929.

12 Huczek Z, Wilimski R, Kochman J, et al. Common carotid artery access for transcatheter aortic valve implantation. Kardiol Pol. 2015; 73: 478-484.

13 Mylotte D, Sudre A, Teiger E, et al. Transcarotid transcatheter aortic valve replacement: Feasibility and safety. JACC Cardiovasc Interv. 2016; 9: 472-480.

14 Kirker EB, Hodson RW, Spinelli KJ, et al. The carotid artery as a preferred alternative access route for transcatheter aortic valve replacement. Ann Thorac Surg. 2017; 104: 621-629.

15 Kappetein AP, Head SJ, Généreux P, et al. Updated standardized endpoint definitions for transcatheter aortic valve implantation: the Valve Academic Research Consortium-2 consensus document. J Thorac Cardiovasc Surg. 2013; 145: 6-23.

16 Hudziak D, Nowak A, Gocoł R, et al. Prospective registry on cerebral oximetry-guided transcarotid TAVI in patients with moderate-high risk aortic stenosis. Minerva Cardioangiol. 2019; 67: 11-18.

17 Grube E, Naber C, Abizaid A, et al. Feasibility of transcatheter aortic valve implantation without balloon pre-dilation: a pilot study. JACC Cardiovasc Interv. 2011; 4: 751-757

18 Overtchouk P, Modine T. Alternate access for TAVI: stay clear of the chest. Interv Cardiol. 2018; 13: 145-150.

19 Adams DH, Popma JJ, Reardon MJ, et al. Transcatheter aortic-valve replacement with a self-expanding prosthesis. N Engl J Med. 2014; 370: 1790-1798.

20 Reardon MJ, Adams DH, Coselli JS, et al. Selfexpanding transcatheter aortic valve replacement using alternative access sites in symptomatic patients with severe aortic stenosis deemed extreme risk of surgery. J Thorac Cardiovasc Surg. 2014; 148: 2869-2876.

21 Kumar N, Khera R, Fonarow GC, et al. Comparison of outcomes of transfemoral versus transapical approach for transcatheter aortic valve implantation. Am J Cardiol. 2018; 122: 1520-1526.

22 North American Symptomatic Carotid Endarterectomy Trial Collaborators; Barnett HJM, Taylor DW, Haynes RB, et al. Beneficial effect of carotid endarterectomy in symptomatic patients with high-grade carotid stenosis. N Engl J Med. 1991; 325: 445-453.

23 Wee IJY, Stonier T, Harrison M, et al. Transcarotid transcatheter aortic valve implantation: a systematic review. J Cardiol. 2018; 71: 525-533.

24 Chamandi C, Abi-Akar R, Rodés-Cabau J, et al. Transcarotid compared with other alternative access routes for transcatheter aortic valve replacement. Circ Cardiovasc Interv. 2018; 11: e006388.

25 Zhao A, Minhui H, Li X, et al. A meta-analysis of transfemoral versus transapical transcatheter aortic valve implantation on 30-day and 1-year outcomes. Heart Surg Forum. 2015; 18: 161-166.

26 Liu Z, He R, Wu C, et al. Transfemoral versus transapical aortic implantation for aortic stenosis based on no significant difference in logistic EurOSCORE: a meta-analysis Thorac Cardiovasc Surg. 2016; 64: 374-381.

27 Debry N, Delhaye C, Azmoun A, et al. Transcarotid transcatheter aortic valve replacement: general or local anesthesia. JACC Cardiovasc Interv. 2016; 9: 2113-2120.

28 Stańska A, Fijałkowska J, Targoński R, et al. Transcatheter aorticvalve implantation through a transcarotid approach and cerebral injury. Kardiol Pol. 2020; 78: 756-758.

29 Watanabe M, Takahashi S, Yamaoka H, et al. Comparison of transcarotid vs. transfemoral transcatheter aortic valve implantation. Circ J. 2018; 82: 2518-2522.

30 Overtchouk P, Modine T. A comparison of alternative access routes for transcatheter aortic valve implantation. Expert Rev Cardiovasc Ther. 2018; 16: 749-756.

31 Villecourt A, Faroux L, Muneaux A, et al. Comparison of clinical outcomes after transcarotid and transsubclavian versus transfemoral transcatheter aortic valve implantation: a propensity-matched analysis. Arch Cardiovasc Dis. 2020; 113: 189-198.

32 Piroli F, Franchin L, Bruno F, et al. New advances in the prevention of transcatheter aortic valve implantation failure: current and future perspectives. Kardiol Pol. 2020; 78: 842-849.

33 Beurtheret S, Karam N, Resseguier N, et al. Femoral versus nonfemoral peripheral access for transcatheter aortic valve replacement. J Am Coll Cardiol. 2019; 74: $2728-2739$

34 Folliguet TA, Teiger E, Beurtheret $\mathrm{S}$, et al. Carotid versus femoral access for transcatheter aortic valve implantation: a propensity score inverse probability weighting study. Eur J Cardiothorac Surg. 2019; 56: 1140-1146. 